\title{
Standard Blood Tests Indicate Changes of Toxocariasis in Carnivores
}

\author{
Olga Panova ${ }^{1}$, Aleksandr Khrustalev${ }^{1}$, Natalia Sysoeva² ${ }^{2}$ Maria Baranova ${ }^{1}$, Igor \\ Glamazdin², and Galina Kryukovskaya ${ }^{2}$ \\ ${ }^{1}$ Laboratory of Biology and Biological Fundamentals of Prevention, Federal State Budget \\ Scientific Institution "Federal Scientific Centre VIEV", Moscow, Russia \\ ${ }^{2}$ Department of Veterinary Medicine, Moscow State University of Food Production, Moscow, \\ Russia
}

ORCID:

Olga Panova: http://orcid.org/0000-0001-9254-0167

Corresponding Author:

Olga Panova

panova@vniigis.ru

Published: 5 April 2021

Publishing services provided by Knowledge E

(c) Olga Panova et al. This article is distributed under the terms of the Creative Commons

Attribution License, which permits unrestricted use and redistribution provided that the original author and source are credited.

Selection and Peer-review under the responsibility of the DonAgro Conference Committee.

\section{Abstract}

This study presents the main changes in the biochemical and hematological blood parameters of dogs and cats infected with toxocara. Presented data are based on the animal's age and welfare. The authors conclude that the pattern of hematological disorders is most pronounced in young animals and proceeds with signs of general intoxication and sensibilizationof the body, hypoxia, anemia and damage to the internal organs (liver and pancreas).

Keywords: hematological studies, biochemical studies, toxocariasis, Toxocara canis, T. cati.

\section{Introduction}

Many parasitic diseases of carnivores are zoonotic and pose a danger to both animals and humans [1]. The domestic animals are considered the main carriers of toxocariasis [1-3]. Eggs are highly resistant to destruction in the environment and can remain invasive for a long time, creating a threat to public health [4].

Issues of timely diagnosis of toxocariasis in animals remain relevant. An integrated approach to identifying concomitant pathology with intestinal infection and its timely relief is important in animal medicine. One of the main indicators revealing the picture of metabolism in animals is blood $[5,6]$. Hematological and biochemical blood parameters can respond with changes to invasions that occur secretly, and to the initial stages of the disease with no clinical diagnosis.

Despite active research in the field of clinical parasitology of domestic carnivores [79], changes in the hematological status with toxocariasis is not yet sufficiently studied. 
In addition, to date, the clinical characteristics of toxocariasis infestation in cats have remained largely unexplored.

The aim of the study is to identify the pathological effects on the naturally infected dogs and cats Toxocara spp. by changes in clinical, hematological and biochemical blood parameters within the conditions of detention.

\section{Methods and Equipment}

The experiment included animals naturally infected Toxocara spp.. Coprological studies of dogs and cats feces were carried out by flotation with a solution of sodium nitrate (NaNO3, SG =1.32) [10]. Animals were divided into groups according to age and habitat.

The study included 44 dogs with natural Toxocara canis infection. 35 out of 44 were divided into groups: 24 from the street and 11 domestic animals, aged 1.5 to 9 months. 9 adult dogs kept at home age from 1.5 years to 5 . The control group included 8 puppies of 4-6 months of age and 10 adult dogs (older than 1 year) not having the propagative stages of parasites in the intestine.

There were 23 cats with $T$. cati natural infectionselected for the experiment. Of these, 17 kittens are aged 2 to 10 months. Animals were divided into groups according to the habitat: domestic kittens born at home from domestic cats - 5 , and kittens picked up from the street or born in shelters -13 . The control group included kittens of 5-6 months of age, free from intestinal nematodes -10 . Adult cats with confirmed intestinal toxocariasis -6 . The control group included 8 adult cats showing no propagative stages of parasites in the intestine.

Blood was taken from animals for analysis in the morning from vena saphena in plastic tubes for hematological analysis of $2.0 \mathrm{ml}$ containing EDTA for biochemical studies of a $3 \mathrm{ml}$ tube. A blood test was performed within 4 hours after taking.

Clinical blood tests were performed on ABC VET hematology analyzer (France). Blood smears were stained hematoxylin-eosin, examined the morphology of blood elements and counted white blood cells. Blood serum was obtained after settling whole blood and retracting a blood clot, followed by centrifugation at $2000 \mathrm{rpm}$ for 10-15 minutes. Samples with hemolysis and chiles were not used. The biochemical $(\mathrm{BH})$ composition of blood serum was studied on a Humalizer Junior automatic biochemical analyzer with the determination of a detailed profile of indicators ( 24 points).

Data were analyzed in accordance with the guidelines for hematology in dogs and cats A.H. Rebar et al. (2001) [5] and the diagnostic manual and atlas of J.W. Harvey (2012) [6]. 
The reliability of the results relative to each other and relative to the norm was evaluated by the standard student criterion. Values of $\mathrm{P}<0.05$ were considered significant. All analyses were performed using SPSS software for Windows version 20.

\section{Results}

The results of clinical, hematological and biochemical blood tests dogs and cats of naturally infection are the following:

Clinical, hematological and biochemical changes in blood serum of dogs naturally infected Toxocara canis. The research results are shown in tables 1 and 2 .

The average value of the erythrocyte index at home puppies was at the lower limit of the norm of $5.46 \pm 0.6 \times 106 / \mu l$. In stray puppies the changes were moreexpressed. Red blood cells- $4.11 \pm 0.4 \times 106 / \mu l$, hemoglobin $-101.0 \pm 4.7 \mathrm{~g} / \mathrm{l}$ and hematocrit $28.77 \pm 1.8 \%$ were reduced. At the upper border were leukocyte counts a $14.77 \pm 1.1 \mathrm{x}$ $10^{3} / \mu$ l, lymphocytes $33.9 \pm 2.8 \%$ and eosinophils $6.5 \pm 1.0 \%$.

In $75 \%$ of the examined stray puppies (18), the level of red blood cells was reduced relative to normal values with a minimum level of $3.97 \times 106 / \mu l$. In $62.5 \%$ of puppies 15 , hematocrit was reduced to $24.2 \%$ and hemoglobin to $96 \mathrm{~g} / \mathrm{dl}$ (minimum values). The $50 \%$ of samples (12 puppies) showed the level of lymphocytes was increased (maximum $38 \%$ ). The $20.8 \%$ (5 puppies) leukocytosis was $22.7 \times 10^{3} / \mu l$.

Hematological parameters in adult infected $T$. canis dogs and animals of control groups meet the physiological norm.

According to the results of $\mathrm{BH}$ studies indomestic puppies, an increase in the values of aspartate aminotransferase (AST) is observed - $43.3 \pm 4.9 \mathrm{IU} / \mathrm{L}$, alanine aminotransferase $(A L T)-58.1 \pm 8.2 \mathrm{IU} / \mathrm{L}$, alkaline phosphatase $(A L P)-85.3 \pm 5.5 \mathrm{IU} / \mathrm{L}$. Decrease in glucose $-4.2 \pm 0.56 \mathrm{Umol} / \mathrm{L}$ and sodium $-145.66 \pm 1.3 \mathrm{Umol} / \mathrm{L}$ to the level of the lower normal values (Table 2).

Stray puppies show an increase in AST values of $80.1 \pm 9.6 \mathrm{IU} / \mathrm{L}, \mathrm{ALT}-76.4 \pm 11.6$ $\mathrm{IU} / \mathrm{L}, \mathrm{ALP}-107.9 \pm 17.6 \mathrm{IU} / \mathrm{L}$, lipases $-32.2 \pm 7.9 \mathrm{IU} / \mathrm{L}$. Decrease in glucose $-3.85 \pm$ $0.9 \mathrm{mmol} / \mathrm{l}$, total protein $-43.4 \pm 6.2 \mathrm{~g} / \mathrm{l}$. Iron ions $19.6 \pm 4.8 \mathrm{mmol} / \mathrm{L}$, potassium ions $4.18 \pm 0.8 \mathrm{mmol} / \mathrm{L}$ and sodium $144.4 \pm 5.5 \mathrm{mmol} / \mathrm{L}$ were at the lower boundary of the norm.

In adult dogs, when compared with the norm, only AST $57.6 \pm 28.9$ IU / L was overestimated, and the total protein content in the blood serum was $60.2 \pm 5.5 \mathrm{~g} / \mathrm{L}$ at 
TABLE 1: Hematological studies of puppies naturally infected T. canis

\begin{tabular}{|c|c|c|c|c|c|}
\hline \multirow[t]{2}{*}{ Indicator } & \multirow[t]{2}{*}{ Units } & \multirow[t]{2}{*}{ Norm } & \multicolumn{3}{|c|}{ Puppies } \\
\hline & & & Domestic & Stray & Control group \\
\hline RBC & x106/pl & $5.5-8.5$ & $5.46 \pm 0.6$ & $4.11 \pm 0.4$ & $8.4 \pm 0.5$ \\
\hline WBC & x $10^{3} / \mu l$ & $6.0-14.0$ & $9.27 \pm 0.9$ & $14.77 \pm 1.1$ & $10.3 \pm 1.0$ \\
\hline $\mathrm{HB}$ & g/per L & $120-180$ & $164.5 \pm 5.4$ & $101.0 \pm 4.7$ & $121.3 \pm 5.3$ \\
\hline $\mathrm{HCT}$ & $\%$ & $39.0-52.0$ & $49.47 \pm 2.1$ & $28.77 \pm 1.8$ & $39.9 \pm 2.4$ \\
\hline ESR & $\mathrm{mm} / \mathrm{h}$ & $1.0-3.5$ & $1.25 \pm 0.1$ & $2.60 \pm 0.2$ & $3.4 \pm 0.3$ \\
\hline PLT & x $10^{3} / \mu 1$ & $160.0-430.0$ & $253.0 \pm 16.3$ & $343.4 \pm 19.2$ & $407.5 \pm 20.7$ \\
\hline MCV & $\mu m^{3}$ & $62.0-77.0$ & $68.0 \pm 3.4$ & $69.9 \pm 3.3$ & $63.7 \pm 3.1$ \\
\hline $\mathrm{MCHC}$ & $\%$ & $32.0-38.0$ & $33.0 \pm 2.1$ & $35.2 \pm 2.4$ & $34.1 \pm 2.2$ \\
\hline RDW & $\%$ & $14.0-18.0$ & $16.9 \pm 1.5$ & $18.6 \pm 1.9$ & $16.23 \pm 1.7$ \\
\hline $\mathrm{MCH}$ & $\mathrm{P} / \mathrm{kg}$ & $21.0-27.0$ & $23.2 \pm 1.8$ & $24.62 \pm 2.1$ & $26.2 \pm 1.9$ \\
\hline \multicolumn{6}{|c|}{ Leucogram: } \\
\hline MON & $\%$ & $2.0-5.0$ & $5.5 \pm 0.5$ & $5.24 \pm 0.7$ & $2.6 \pm 0.2$ \\
\hline LYM & $\%$ & $12.0-30.0$ & $32.5 \pm 2.5$ & $33.9 \pm 2.8$ & $26.8 \pm 1.9$ \\
\hline BAS & $\%$ & $0-1$ & $0 \pm 0.0$ & $0 \pm 0.0$ & $0 \pm 0.0$ \\
\hline EOS & $\%$ & $0-5$ & $5.5 \pm 0.8$ & $6.5 \pm 1.0$ & $4.5 \pm 0.7$ \\
\hline \multicolumn{6}{|c|}{ Neutrophilic granulocyte: } \\
\hline A band cell & $\%$ & $0-3$ & $1.5 \pm 0.09$ & $1.27 \pm 0.12$ & $1.75 \pm 0.17$ \\
\hline Segmented & $\%$ & $60-70$ & $53.0 \pm 3.6$ & $53.4 \pm 3.4$ & $64.5 \pm 4.8$ \\
\hline
\end{tabular}

the lower boundary. Clinical, hematological and biochemical changes in blood serum of cats naturally infected Toxocara cati. The results are shown in tables 3 and 4.

According to the results of hematological studies in domestickittens, the average value of the erythrocyte index was at the lower limit of the norm of $5.4 \pm 1.2 \times 106 / \mathrm{\mu l}$, the level of leukocytes was overestimated for $19.4 \pm 3.8 \times 106 / \mu l$. The changes in stray kittens were moreexpressed. Red blood cells are underestimated - $4.3 \pm 1.0 \times 106 / \mu$, hemoglobin $-62.0 \pm 4.8 \mathrm{~g} / \mathrm{l}$, the average concentration of hemoglobin in the red blood cell is $24.0 \pm 2.0 \%$. At the upper border, leukocyte counts are $27.1 \pm 3.3 \times 10^{3} / \mu$ land the width of the distribution of red blood cells is $23.6 \pm 2.8 \%$ (Table 3).

Hematologic indicators in adult cats infected $T$. cati and animals of control groups were within the physiological norm.

An increase in AST values is observed according to the results of the studies in domestic kittens $-46.3 \pm 9.4 \mathrm{IU} / \mathrm{L}, \mathrm{ALT}-60.1 \pm 11.4 \mathrm{IU} / \mathrm{L}$. As for stray kittens, an increase in AST values is observed $-80.1 \pm 16.6 \mathrm{IU} / \mathrm{L}, \mathrm{ALT}-76.4 \pm 13.6 \mathrm{IU} / \mathrm{L}$, and alkaline phosphatase $-107.9 \pm 30.6 \mathrm{IU} / \mathrm{L}$. The decrease in total protein is $42.4 \pm 11.2$ g/l and CPK $-134.4 \pm 41.4 \mathrm{IU} / \mathrm{L}$. 
TABLE 2: Biochemical studies serum of puppies naturally infected T. canis

\begin{tabular}{|c|c|c|c|c|c|}
\hline \multirow[t]{2}{*}{ Indicators } & \multirow[t]{2}{*}{ Units } & \multirow[t]{2}{*}{ Norms } & \multicolumn{3}{|c|}{ Puppies } \\
\hline & & & Domestic & Stray & Control group \\
\hline Total bilirubin & Umol/L & $3.5-13$ & $8.7 \pm 2.2$ & $7.7 \pm 2.6$ & $6.8 \pm 2.6$ \\
\hline Direct bilirubin & Umol/L & 0 & $0.00 \pm 0.0$ & $0.00 \pm 0.0$ & $0.00 \pm 0.0$ \\
\hline Aspartate transaminase (AST) & $\mathrm{IU} / \mathrm{L}$ & $0-40$ & $43.3 \pm 4.9$ & $80.1 \pm 9.6$ & $27.3 \pm 9.6$ \\
\hline Alanine transaminase (ALT) & $\mathrm{IU} / \mathrm{L}$ & $0-55$ & $58.1 \pm 8.2$ & $76.4 \pm 9.6$ & $35.6 \pm 9.4$ \\
\hline AST/ALT ratio & & $0.75-1.4$ & $0.97 \pm 0.1$ & $1.21 \pm 0.2$ & $1.10 \pm 0.3$ \\
\hline Urea & Umol/L & $3.1-8.5$ & $6.25 \pm 1.1$ & $6.14 \pm 1.5$ & $5.68 \pm 1.1$ \\
\hline Creatinin & Umol/L & $55-106$ & $81.3 \pm 11.7$ & $93.1 \pm 17.3$ & $82.8 \pm 13.9$ \\
\hline Protein & g per $L$ & $60-72$ & $53.1 \pm 3.1$ & $43.4 \pm 6.2$ & $67.2 \pm 3.2$ \\
\hline Albumen & $g$ per $\mathrm{L}$ & $26-39$ & $31.8 \pm 3.0$ & $30.2 \pm 7.4$ & $31.4 \pm 2.8$ \\
\hline Alkaline phosphatase & $\mathrm{IU} / \mathrm{L}$ & $0-75$ & $85.3 \pm 5.5$ & $107.9 \pm 17.6$ & $46.3 \pm 11.7$ \\
\hline Alpha-amylase & $\mathrm{IU} / \mathrm{L}$ & $0-1800$ & $895.55 \pm 361.3$ & $1104.58 \pm 35.1$ & $912.40 \pm 26.7$ \\
\hline Lipase & $\mathrm{IU} / \mathrm{L}$ & $0-30$ & $19.9 \pm 6.7$ & $32.2 \pm 7.9$ & $20.5 \pm 5.1$ \\
\hline Glucose & Umol/L & $4.4-6.5$ & $4.2 \pm 0.56$ & $3.85 \pm 0.9$ & $5.38 \pm 0.6$ \\
\hline Lactate dehydrogenase & Umol/L & $0-350$ & $195.9 \pm 22.6$ & $247.8 \pm 23.0$ & $248.6 \pm 24.1$ \\
\hline Cholesterol & Umol/L & $2.9-6.0$ & $4.36 \pm 0.8$ & $5.33 \pm 11.8$ & $4.37 \pm 0.8$ \\
\hline Triacylglycerol & Umol/L & $0.45-1.1$ & $0.81 \pm 0.1$ & $0.77 \pm 0.1$ & $0.83 \pm 0.1$ \\
\hline Creatine kinase (CK) & $\mathrm{IU} / \mathrm{L}$ & $32-154$ & $107.7 \pm 33.9$ & $184.4 \pm 21.9$ & $120.3 \pm 21.2$ \\
\hline Potassium & Umol/L & $4.2-5.5$ & $4.84 \pm 0,3$ & $4.18 \pm 0.8$ & $4.99 \pm 0.2$ \\
\hline Sodium & Umol/L & $145-150$ & $145.6 \pm 1.3$ & $144.4 \pm 5.5$ & $147.2 \pm 1.0$ \\
\hline Phosphorus & Umol/L & $1.1-1.8$ & $1.44 \pm 0.1$ & $1.49 \pm 0.3$ & $1.48 \pm 0.2$ \\
\hline Calcium & Umol/L & $2.3-2.8$ & $2.44 \pm 0.1$ & $2.50 \pm 0.2$ & $2.48 \pm 0.1$ \\
\hline Iron ions & Umol/L & $19.8-32$ & $25.2 \pm 2.8$ & $19.6 \pm 4.8$ & $26.8 \pm 3.8$ \\
\hline Magnesium & Umol/L & $0.86-1.07$ & $0.93 \pm 0.2$ & $0.88 \pm 0.1$ & $0.95 \pm 0.05$ \\
\hline
\end{tabular}

Potassium ions $-3.58 \pm 0.5 \mathrm{Umol} / \mathrm{L}$ and sodium $-144.4 \pm 6.5 \mathrm{Umol} / \mathrm{L}$ were at the lower boundary of the norm (Table 4).

\section{Discussion}

The red blood cells, hemoglobin and hematocrit decrease in young animals indicates the development of anemia. An increase in the concentration of folates and a decrease in cobalt-containing biologically active substances (vitamin B12) are used to assess a decrease in the functioning of the mucous membrane of the proximal small intestine $[11,12]$. The study suggests the mechanism of the development of anemia is due to the absorption capacity violation of the mucous membrane invaded with toxocara. 
TABLE 3: Hematological indicators of kittens infected $T$. cati

\begin{tabular}{|c|c|c|c|c|c|}
\hline \multirow[t]{2}{*}{ Indicators } & \multirow[t]{2}{*}{ Units } & \multirow[t]{2}{*}{ Norms } & \multicolumn{3}{|c|}{ Kittens } \\
\hline & & & Domestic & Stray & Control group \\
\hline RBC & x $10^{6} / \mu 1$ & $5.5-10$ & $5.4 \pm 1.2$ & $4.3 \pm 1.0$ & $8.4 \pm 2.0$ \\
\hline WBC & x $10^{3} / \mu l$ & 5.5-19.5 & $19.4 \pm 3.8$ & $27.1 \pm 3.3$ & $12.3 \pm 2.8$ \\
\hline $\mathrm{HB}$ & g/per L & $80-150$ & $101 \pm 5.5$ & $62 \pm 4.8$ & $121 \pm 6.8$ \\
\hline $\mathrm{HCT}$ & $\%$ & $30-47$ & $31.3 \pm 3.2$ & $46.7 \pm 3.6$ & $39.9 \pm 3.4$ \\
\hline ESR & $\mathrm{mm} / \mathrm{h}$ & $0-13$ & $10.9 \pm 1.3$ & $12.4 \pm 1.6$ & $3.4 \pm 2.0$ \\
\hline PLT & x $10^{3} / \mu 1$ & $300-800$ & $355 \pm 18.6$ & $521 \pm 24.1$ & $427 \pm 20.2$ \\
\hline MCV & $\mu m^{3}$ & $43-53$ & $44.3 \pm 2.0$ & $43.5 \pm 2.1$ & $43.7 \pm 1.9$ \\
\hline $\mathrm{MCHC}$ & $\%$ & $30-36$ & $34.9 \pm 4.6$ & $24.0 \pm 2.0$ & $34.1 \pm 2.9$ \\
\hline RDW & $\%$ & $14.0-18.0$ & $16.9 \pm 2.1$ & $23.6 \pm 2.8$ & $16.2 \pm 2.2$ \\
\hline $\mathrm{MCH}$ & $\mathrm{P} / \mathrm{kg}$ & 14-19 & $15.3 \pm 1.8$ & $15.6 \pm 2.0$ & $17.0 \pm 1.9$ \\
\hline \multicolumn{6}{|c|}{ Leucogram: } \\
\hline MON & $\%$ & $1-4$ & $1 \pm 0.06$ & $3 \pm 0.2$ & $1 \pm 0.04$ \\
\hline LYM & $\%$ & $20-55$ & $22 \pm 0.6$ & $16 \pm 0.4$ & $36 \pm 0.8$ \\
\hline BAS & $\%$ & $0-1$ & $0 \pm 0.0$ & $0 \pm 0.0$ & $0 \pm 0.0$ \\
\hline EOS & $\%$ & $2-12$ & $6 \pm 0.2$ & $7 \pm 0.3$ & $5 \pm 0.2$ \\
\hline \multicolumn{6}{|c|}{ Neutrophilic granulocyte: } \\
\hline A band cell & $\%$ & $0-3$ & $7 \pm 0.4$ & $15 \pm 0.6$ & $2 \pm 0.1$ \\
\hline Segmented & $\%$ & $35-75$ & $64 \pm 2.8$ & $59 \pm 2.5$ & $58 \pm 2.4$ \\
\hline
\end{tabular}

$\mathrm{P}<0.05$

Long-term B12 deficiency is a serious disease. It appears within the development of megaloblastic anemia and/or neurological disorders. The disease needs a serious treatment, otherwise it leads to the death of the animal [13]. Cats react especially sensitively and hard to a deficiency of cobalt-containing biologically active substances. Therefore, it is important to prescribe parenteral administration of cobalamin in a timely manner [14].

When registering anemia in animals aged up to a year the toxocariasis needs to be excluded. On the other hand, with the described diagnosis of this disease, it is important to prescribe hematological studies additionally and cut down the development of anemia.

An increase in the number of leukocytes and lymphocytes is provoked by the migration of larvae and causes an organism's response to tissue trauma. The increase in the number of eosinophils is obviously due to the response to the products of the metabolism of nematodes in the form of an allergic reaction. It is believed that peripheral blood eosinophilia, although not specific for toxocarainfection, is associated with the process of active migration of larvae [15]. 
TABLE 4: Biochemical studies serum of kittens naturally infected $T$. cati

\begin{tabular}{|c|c|c|c|c|c|}
\hline \multirow[t]{2}{*}{ Indicators } & \multirow[t]{2}{*}{ Units } & \multirow[t]{2}{*}{ Norms } & \multicolumn{3}{|c|}{ Kittens } \\
\hline & & & Domestic & Stray & Control group \\
\hline Total bilirubin & Umol/L & $0-10$ & $4.6 \pm 1.8$ & $8.4 \pm 2.2$ & $4.6 \pm 1.6$ \\
\hline Direct bilirubin & Umol/L & $0-4,9$ & $0.00 \pm 0.0$ & $0.00 \pm 0.0$ & $0.00 \pm 0.0$ \\
\hline Aspartate transaminase (AST) & IU/L & $12-47$ & $46.3 \pm 9.4$ & $80.1 \pm 8.6$ & $36.8 \pm 5.4$ \\
\hline Alanine transaminase (ALT) & IU/L & $19-60$ & $60.1 \pm 8.9$ & $76.4 \pm 9.6$ & $48.1 \pm 3.1$ \\
\hline AST/ALT ratio & & $1.1-1.3$ & $1.0 \pm 0.03$ & $1.27 \pm 0.08$ & $1.24 \pm 0.2$ \\
\hline Urea & Umol/L & $5.4-12.1$ & $8.55 \pm 2.3$ & $5.10 \pm 1.5$ & $7.85 \pm 1.7$ \\
\hline Creatinin & Umol/L & $70-165$ & $98.6 \pm 18.7$ & $103.6 \pm 23.4$ & $72.1 \pm 14.5$ \\
\hline Protein & $\mathrm{g} /$ per $\mathrm{L}$ & $56-77$ & $63.7 \pm 13.1$ & $42.4 \pm 11.2$ & $64.4 \pm 14.8$ \\
\hline Albumen & $g /$ per $L$ & $25-39$ & $27.8 \pm 14.0$ & $29.1 \pm 16.5$ & $33.0 \pm 17.8$ \\
\hline Alkaline phosphatase & $\mathrm{IU} / \mathrm{L}$ & $30-130$ & $44.3 \pm 11.5$ & $107.9 \pm 30.6$ & $76.3 \pm 18.4$ \\
\hline Alpha-amylase & IU/L & $500-1250$ & $436.5 \pm 38.3$ & $1146.4 \pm 45.5$ & $721.1 \pm 36.7$ \\
\hline Lipase & $\mathrm{IU} / \mathrm{L}$ & $0-30$ & $23.4 \pm 8.1$ & $18.8 \pm 7.5$ & $24.8 \pm 6.5$ \\
\hline Glucose & Umol/L & $3.3-6.6$ & $4.0 \pm 0.6$ & $3.5 \pm 0.4$ & $5.0 \pm 0.5$ \\
\hline Lactate dehydrogenase & $\mathrm{IU} / \mathrm{L}$ & $35-500$ & $213.4 \pm 20.2$ & $208.1 \pm 21.4$ & $313.1 \pm 30.1$ \\
\hline Cholesterol & Umol/L & $1.9-3.9$ & $3.6 \pm 0.6$ & $2.3 \pm 1.2$ & $3.7 \pm 0.9$ \\
\hline Triacylglycerol & Umol/L & $0.38-1.1$ & $0.62 \pm 0.28$ & $0.97 \pm 0.31$ & $0.71 \pm 0.26$ \\
\hline Creatine kinase (CK) & IU/L & $180-814$ & $254.7 \pm 23.1$ & $134.4 \pm 41.4$ & $218.0 \pm 22.7$ \\
\hline Potassium & Umol/L & $3.6-5.5$ & $4.35 \pm 0.6$ & $3.58 \pm 0.5$ & $4.27 \pm 0.4$ \\
\hline Sodium & Umol/L & $144-158$ & $146.5 \pm 4.1$ & $144.4 \pm 6.5$ & $149.2 \pm 5.1$ \\
\hline Phosphorus & Umol/L & $2.1-2.8$ & $1.53 \pm 0.32$ & $1.84 \pm 0.56$ & $1.53 \pm 0.44$ \\
\hline Calcium & Umol/L & $2.0-2.7$ & $2.34 \pm 0.1$ & $2.12 \pm 0.1$ & $2.24 \pm 0.1$ \\
\hline Iron ions & Umol/L & $12.0-39.0$ & $25.6 \pm 2.0$ & $18.9 \pm 1.6$ & $22.8 \pm 2.3$ \\
\hline Magnesium & Umol/L & $0.8-1.15$ & $0.98 \pm 0.06$ & $0.89 \pm 0.04$ & $0.91 \pm 0.07$ \\
\hline
\end{tabular}

In a biochemical blood test, an increase in AST, ALT and alkaline phosphatase is observed. This is due to the fact that the migration of Toxocara larvae passes through parenchymal organs, primarily, through the liver. An increase in enzymes is directly proportional to the damage to hepatocytes. The decrease in total protein is explained by the suppression of protein biosynthesis by the liver and insufficient absorption of the mucous membrane of the small intestine [16]. Impaired absorption in the intestine also leads to a decrease in total protein, iron, potassium and sodium ions.

According to Kondrakhin I.P. (1985), hypoglycemia appears as a result of disordered nervous system and the influence of catecholamines ejected in blood within a decrease in glucose concentration [17].

An increase in lipase indicates an inflammatory process in the pancreas. With inflammation of the duodenum, the outflow of pancreatic secretion is disrupted, as a result 
of which it accumulates in the pancreas itself, causing damage to it, leading to an inflammatory reaction.

The outlined general image of hematological disorders is mostly spread among puppies. In this age group the toxocariasis infestation proceeds with symptoms of general intoxication and sensibilization of the body, hypoxia, anemia and damage to internal organs (liver, pancreas).

As for adult dogs, there are no specific significant changes.

When testing groups ofkittens, the level of red blood cells is underestimated and leukocytes are overestimated. In stray kittenss, hemoglobin and the average concentration of hemoglobin in the red blood cell are underestimated. The result is similar to the result of the group withpuppies.

Biochemical studies of kittensshowed an increase in AST and ALT in all groups. In straykittens: alkaline phosphatase is also overestimated, total protein and creatinine phosphokinase, potassium and sodium ions are reduced. In adult cats invaded by toxocara: blood counts are normal for this species.

The veterinary practice interpret the changes described above as a digestive disorder of unknown etiology, a viral infection or intoxication of the body [17]. The data presented in the study show that a similar pathological picture, especially in young animals, can be caused by toxocariasis infestation. Its exclusion requires a helminth-coprological study.

According to the observations, puppieswith good nutrition when naturally invaded with toxocara the changes in blood tests become gradually normalizing. It is explained due to the compensation processes of the body.

The data obtained by us coincide with the studies of A. Mikhin. (2004), Demina V.A. (2007), Akimova S.A. (2008). In the cited works, data on a single experimental infection of puppies with high doses of invasive eggs are presented [7-9]. In vivo, infection, as a rule, has a more gradual nature and the possibility of reinfestation. Thus, the study of the toxocariasis effect on the animal's organism was studied mainly inpuppies. The resources did not provide any data on the effects of toxocariasis in cats.

\section{Conclusion}

Generalizing the group of animals aged up to one year old (puppiesand kittens), the study presents the following: the toxocariasis occurs with signs of general intoxication and sensibilizationof the body, hypoxia, anemia and damage to the internal organs (liver and pancreas). When there are symptoms and diagnosis of toxocariasis revealed, it is 
important for animals to prescribe hematological test and cut down the development of anemia as well as other concomitant pathologies. In the opposite, toxocariasis infestation can cause anemia by blood tests in young animals. Its exclusion requires helminth-coprological examination..

\section{References}

[1] Deplazes, P., et al. (2011). Role of Pet Dogs and Cats in the Transmission of Helminthic Zoonoses in Europe, with a Focus on Echinococcosis and Toxocarosis. Veterinary Parasitology., vol. 182, pp. 41-53. doi: 10.1016/j.vetpar.2011.07.014.

[2] Lee, A. C., et al. (2010). Epidemiologic and Zoonotic Aspects of Ascarid Infections in Dogs and Cats. Trends in Parasitology., vol. 26, pp. 155-61. doi: 10.1016/j.pt.2010.01.002

[3] Panova, O. A., Glamazdin, I. G. and Spiridonov, S. E. (2015). Epidemiological Aspects of Animal Toxocariasis in a Megalopolis. Medical Parasitology and Parasitic Diseases., vol. 3, pp. 39-41.

[4] De Silva, N. R., et al. (2003). Soil-Transmitted Helminth Infections: Updating the Global Picture. Trends in Parasitology., vol. 19, issue 12, pp. 547-51. https://doi.org/ 10.1016/j.pt.2003.10.002

[5] Rebar, A. H., et al. (2001). Guide to Hematology in Dogs and Cats. Teton: New Media, p. 264.

[6] Harvey, J. W. (2012). Veterinary Hematology: A Diagnostic Guide and Color Atlas. Saunders/Elsevier, St. Louis, MO , p. 360. https://doi.org/10.1111/vcp.12007

[7] Mikhin, A. G. (2004). Oxocariasis of a Dog: Epizootology, Immuno-Diagnostics, Pathomorphology, Treatment. PhD thesis in Veterinary Sciences, Nizhny Novgorod, p. 119.

[8] Demin, V. A. (2007). Toxocariasis of the Dog and the Improvement of Measures to Combat It. PhD thesis in Veterinary Sciences, Moscow, p. 122.

[9] Akimova, S. A. (2008). Host-Parasitic Relationships and Dynamics of Hematological Parameters in Dogs with Toxocariasis. Bulletin of the Lower Volga Agro-University Complex: Science and Higher Professional Education, .vol. 2, issue 10, pp. 89-91.

[10] Zajac, A. M. and Conboy, G. A. (2012). Veterinary Clinical Parasitology, 8rd ed. WileyBlackwell, Chichester, p. 368.

[11] Fyfe, J. C. (2004). The Functional Cobalamin (Vitamin B12) - Intrinsic Factor Receptor is a Novel Complex of Cubilin and Amnionless. Blood., vol. 103, pp. 1573-9. doi: 10.1182/blood-2003-08-2852 
[12] Hall, E., Simpson, J. and Williams, D. (2010). Gastroenterology of Dogs and Cats. Moscow: Aquarium Print, p 408.

[13] Reynolds, E. (2006). Vitamin B12, Folic Acid, and the Nervous System. The Lancet. Neurology, vol. 5, pp. 949-60. doi: 10.1016/S1474-4422(06)70598-1

[14] Lutz, S., et al. (2013). Clinical and Laboratory Findings in Border Collies with Presumed Hereditary Juvenile Cobalamin Deficiency. Journal of the American Animal Hospital Association. vol. 49, pp. 197-203. doi: 10.5326/JAAHA-MS-5867

[15] Magnaval, J-F., et al. (2001). Highlights of Human Toxocariasis. The Korean journal of parasitology., vol. 39, issue 1, pp. 1-11. doi: 10.3347/kjp.2001.39.1.1

[16] Chala, I. V. and Bahur, T. I. (2016). Biochemical Changes and Redox Potential of Blood of Dogs with Toxocariasis. In Parasitic Systems and Parasitocenoses of Animals. Vitebsk: VGAVM, vol. 5, pp. 189-191.

[17] Kondrakhin, I. P., Kurilov, N. V. and Malakhov, A. G. (1985). Clinical Laboratory Diagnostics in Veterinary Medicine, Moscow: Agropromizdat, p. 287. 